\title{
A luta contra o desemprego: os portões de fogo da atualidade
}

Luciano Somenzari

Jornalista, especialista em Gestão de Processos Comunicacionais, diretor de comunicação da Prefeitura de Santo André.

E-mail: lucianosomenzari@uol.com.br

Como a comunicação pode auxiliar na batalha contra o desemprego, problema que afeta milhões de famílias brasileiras? Esse é o tema geral do projeto de pesquisa desenvolvido no curso de Gestão da Comunicação, apresentado à matriz da Central de Trabalho e Renda - CTR, ligada à Central Única dos Trabalhadores - CUT, localizada na cidade de Santo André, na região do ABC paulista ${ }^{1}$.

A Central de Trabalho e Renda é uma agência pública de emprego que oferece gratuitamente ao trabalhador sem ocupação profissional serviços para sua recolocação no mercado formal de trabalho, além de orientação a fim de que ele possa buscar outras possibilidades de renda, por meio de cooperativas, empresas de autogestão, empreendedorismo popular etc. Dentro da concepção de funcionamento da CTR, há uma nítida preocupação com vários aspectos da formação humana do trabalhador, relacionados à cidadania e à consciência política, que podem ser entendidos como elementos de apoio a atitudes que, em última instância, buscam coletivamente o combate das injustiças sociais.

Passam diariamente pela CTR em Santo André cerca de 600 pessoas, em média, que esperam por volta de duas horas para serem atendidas. Convém esclarecer que também existem unidades em outras cidades da região e em São Paulo; no entanto, esta pesquisa ficou restrita à matriz, por atender um número maior de pessoas.

Além da CUT, a agência também tem como parceira a Prefeitura de Santo André, que contribui financeiramente para a manutenção da Central e desenvolve programas específicos para o trabalhador, como cursos de Requalificação Profissional, Empreendedor Popular, Incubação de Cooperativas, Banco do Povo (para financiar pequenos negócios), entre outros.

O grande desafio da Central de Trabalho e Renda não é apenas ajudar o trabalhador em plenas condições profissionais a conquistar uma vaga em um

1. ABC paulista, Região do Grande $A B C$ ou $A B C D$ é um conjunto industrial formado por sete municípios da Região Metropolitana de São Paulo: Santo André (A), São Bernardo do Campo (B), São Caetano do Sul (C), 
mercado de trabalho extremamente competitivo, mas auxiliar uma legião de pessoas que dificilmente terão oportunidade de ser empregadas dentro das regras tradicionais da economia capitalista. Para estas, é necessário desenvolver novas possibilidades de obtenção de renda.

O presente trabalho pretende contribuir para a superação desses desafios, utilizando a comunicação e todo seu instrumental teórico e prático. Para tanto, é fundamental entender como se dão os processos de comunicação mantidos pela Central de Trabalho e Renda e, sobretudo, como o trabalhador responde a eles, a partir do seu contexto social, econômico e cultural. Esse entendimento precisa ser fundamentado em bases científicas com os devidos critérios metodológicos de pesquisa, sem os quais qualquer proposta de intervenção em um processo comunicacional, objetivo deste trabalho, cairá na vala do senso comum.

\section{DESEMPREGO: O FLAGELO NACIONAL}

O fenômeno do desemprego começou a atingir com mais contundência a População Economicamente Ativa (PEA) no Brasil a partir dos anos 1980. Por PEA compreende-se as pessoas com mais de 10 anos de idade que se encontram trabalhando ou à procura de emprego.

Da década de 1980 até 1999, o crescimento econômico brasileiro foi, em média, de 2,1\% ao ano, índice bem inferior ao registrado entre os anos de 1950 e 1980, quando o país dava saltos de crescimentos que batiam a marca dos $7 \%$ ao ano ${ }^{2}$. Com a economia apenas patinando, uma das conseqüências mais diretas têm sido o comprometimento na absorção de mão-de-obra, principalmente dos assalariados com carteira assinada.

Durante a década de 1990, a cada dez empregos criados somente dois eram assalariados, mesmo assim, sem registro formal.

Em 1999, por exemplo, o Brasil assumiu a terceira posição no ranking mundial do desemprego, pois tinha, segundo dados da PNAD (Pesquisa Nacional por Amostra de Domicílios) do IBGE, 7,6 milhões de pessoas sem trabalho. No total, o Brasil perdeu apenas para a Índia, Indonésia e Rússia?

Nos anos 1990, o problema do desemprego se agravou ainda mais depois de uma extraordinária mudança na política econômica inicialmente adotada no governo Fernando Collor de Mello (1990-1992) - posteriormente consolidada

Diadema (D), Mauá, Ribeirão Pires e Rio Grande da Serra. Santo André possui a maior população rotativa, cerca de três milhões de pessoas circulam na cidade todos os dias. [N.E.]

2. POCHMANN, Márcio. $\mathrm{O}$ emprego na globalização. São Paulo: Boitempo, 2002. p. 26.

3. Ibid., p. 28. por Fernando Henrique Cardoso, eleito e reeleito presidente da República (1994-1998 e 1999-2002). Com o argumento de promover mais competitividade na economia brasileira ante os países desenvolvidos, e intenção manifesta de impulsionar o crescimento econômico sustentado por investimentos externos, foi criada no governo Collor a Política Industrial de Comércio Externo (PICE), fundamentada em três pontos básicos:

1) Abertura comercial, que obrigou as empresas brasileiras a investirem em novas tecnologias e a baixarem custos para concorrer com os produtos importados. As empresas do setor secundário da economia que sobrevi- 
veram passaram a demitir em massa trabalhadores, para, posteriormente, contratar mão-de-obra com salários mais baixos e com exigência de qualificações compatíveis com as novas tecnologias de produção.

2) Reformulação do papel do Estado, em que foi promovido um gigantesco processo de privatização de inúmeras empresas públicas, notadamente os setores de telefonia, energético e financeiro. Verificou-se, sobretudo no governo de Fernando Henrique Cardoso, uma imensa transferência de patrimônio público para as mãos do setor privado de capital internacional. Ainda, como parte da reformulação do papel do Estado, foram promovidas importantes reformas na administração pública, a partir de uma definição de Estado Mínimo, ou seja, diminuir ao mínimo o papel do Estado na sociedade, restringindo-o a funções meramente regulatórias e básicas, como o provimento de saúde, segurança e principalmente educação. Um dos corolários dessas medidas foi a chamada flexibilização da mão-de-obra, ou seja, a precarização das relações de trabalho, com aumentos nos índices de subemprego, terceirização de empregados e conseqüente queda de renda dos trabalhadores.

3) Estabilidade monetária ancorada no dólar, como medida para acabar com a hiperinflação, que assolou o Brasil durante quase toda a década de 1980. Com a valorização da moeda nacional ante o dólar houve a clara intenção de incrementar ainda mais as importações e fazer jus à abertura comercial instituída três anos antes. A estabilização monetária através da chamada âncora cambial também contemplava a definitiva inserção do Brasil no mercado mundial, que permitiu novas bases para endividamento externo e atração de investimentos estrangeiros.

\section{O CONSENSO DE WASHINGTON}

Os procedimentos da nova política econômica iniciada no governo Collor e consolidada no governo Fernando Henrique Cardoso são frutos de um conjunto de diretrizes formuladas em 1989 por um grupo de acadêmicos, funcionários de governo e economistas norte-americanos, junto com dirigentes do Banco Mundial e do Fundo Monetário Internacional (FMI). Dessas diretrizes resultou o documento denominado Consenso de Washington, que prega, além dos pontos mencionados e praticados no Brasil a partir de 1990, medidas como o estabelecimento de uma rígida disciplina fiscal, proteção da propriedade privada, priorização de gastos públicos em educação e saúde, implementação de uma ampla desregulamentação econômica, entre outros.

As diretrizes do Consenso de Washington foram largamente utilizadas em vários países da América Latina e acabaram mostrando-se eficientes nas medidas de controle da inflação. Contudo, "no plano social as conseqüências foram desalentadoras: um misto de desemprego, recessão e baixos salários, conjugado com um crescimento econômico insuficiente, revela a outra face dessa moeda" ${ }^{4}$.

4. SANDRONI, Paulo (Ed.). Novíssimo Dicionário de Economia. 6. ed. São Paulo: Best Seller, 2001. p. 213 
5. IANNI, Octavio. Globalização: novo paradigma das Ciências Sociais. Estudos Avançados. São Paulo: USP/IPEA, 1994. vol. 8, 21, p. 154.

6. WALLERSTEIN, Immanuel. Uma política de esquerda para o século XXI? Ou teoria e práxis novamente. In: CEVASCO, Maria E.; LEITE, José C.; LOUREIRO, Isabel (Orgs.). O espírito de Porto Alegre. São Paulo: Paz e Terra, 2002.

7. ANTUNES, Ricardo. Os sentidos do trabalho: ensaios sobre a afirmação e a negação do trabalho. São Paulo: Boitempo, 2003.

8. KURZ, Robert. O colapso da modernização: da derrocada do socialismo de caserna à crise da economia mundial. São Paulo: Paz e Terra, 1993.

9. ANTUNES, Ricardo. Os sentidos do trabalho, op. cit.
A receita preconizada pelo Consenso de Washington chega na esteira do fenômeno da globalização da economia, em que predominam, por exemplo, o livre fluxo internacional de capital financeiro, a expansão de grandes oligopólios transnacionais, a concentração da riqueza entre os países do hemisfério norte em detrimento dos do hemisfério sul. Na verdade, a globalização é um fenômeno que ultrapassa a esfera econômica e atinge todos os aspectos da sociedade contemporânea. Trata-se, nas palavras de Octavio Ianni, de um novo paradigma nas Ciências Sociais, "um universo múltiplo, uma sociedade desigual e contraditória, envolvendo economia, política, geografia, história, cultura, religião, língua, tradição, identidade, etnicismo, fundamentalismo, ideologia, utopia" ${ }^{5}$.

No processo de globalização da economia, o desemprego em alta escala passa a ser configurado como estrutural e perene, não mais fruto de uma simples circunstância dos ciclos alternados de expansão e depressão do atual modo de produção. É tão estrutural quanto a crise do capitalismo. Para autores como Immanuel Wallerstein ${ }^{6}$, Ricardo Antunes ${ }^{7}$ e Robert Kurz ${ }^{8}$, a crescente exaustão da capacidade de expansão do lucro, o conseqüente comprometimento da acumulação do capital, o uso da força de trabalho como um fim em si mesmo e a brutal desigualdade entre países ricos e pobres são sinais expressivos da crise sem precedentes no sistema capitalista.

Como resposta à sua própria crise, iniciou-se um processo de reorganização do capital e de seu sistema ideológico e político de dominação, cujos contornos mais evidentes foram o advento do neoliberalismo, com a privatização do Estado, a desregulamentação dos direitos do trabalho e a desmontagem do setor produtivo estatal, da qual a era Thatcher-Reagan foi expressão mais forte; a isso se seguiu também um intenso processo de reestruturação da produção e do trabalho, com vistas a dotar o capital do instrumental necessário para tentar repor os patamares de expansão anteriores ${ }^{9}$.

Em reação à permanente instabilidade da economia mundial das últimas décadas, os preceitos apregoados pelos economistas e teóricos do Estado Mínimo passam a ser receitados a todos os países pobres como único caminho possível para não apenas enfrentar as constantes crises, mas, sobretudo, adentrar definitivamente ao seleto grupo das nações desenvolvidas. O canto da sereia entoado pela onda liberal capitalista se sentiu desimpedido para invadir os ouvidos de todo o globo, uma vez que o seu contraponto, as economias centralmente planificadas dos países socialistas, havia sucumbido com a queda do Muro de Berlim, no final dos anos 1980.

\section{O PROBLEMA DE PESQUISA}

Diante do cenário macroeconômico exposto, contextualizando o problema estrutural do desemprego na sociedade brasileira, voltamos ao trabalho desenvolvido pela Central de Trabalho e Renda, na cidade de Santo André. Cidade, aliás, de perfil industrial que sofreu imensamente com a fuga, a falência e a 
fusão de empresas, resultado das mudanças econômicas implementadas no início dos anos 1990.

Propomos analisar todo o processo de comunicação relacionado ao atendimento dos trabalhadores, além da relação da CTR com o poder público local e com as empresas localizadas na região do $\mathrm{ABC}$, potenciais empregadoras.

Pretendemos verificar quais as falhas presentes nesse processo e avaliar o que pode ser feito para corrigi-las. A partir de uma análise preliminar, foi possível levantar alguns pressupostos relacionados à comunicação:

- Não existe um planejamento que preveja uma atuação conjunta das ações de comunicação. Percebe-se que a maioria das iniciativas, como a divulgação dos serviços da CTR, é feita isoladamente.

- O trabalhador dispõe de pouquíssimos canais para estabelecer formas de diálogo com a CTR.

- Há deficiências na divulgação das atividades que a CTR desenvolve, à exceção das vagas de trabalho oferecidas.

- Também há deficiências na relação da CTR com o poder público local, agente importantíssimo na formulação e implementação de políticas públicas para o trabalhador.

Por estarmos neste trabalho tratando essencialmente de assuntos relativos a humanidades, cabe jogar mais peso à interpretação dos fatos observados acerca do que Guillermo Orozco Gomes chama de paradigma hermenêutico na produção de conhecimentos.

A importância de ter certa fidelidade na interpretação é a possibilidade não só de entender, mas de modificar aquilo que se entende, e de poder alcançar novos conhecimentos mais profundos ou mais amplos de um primeiro conhecimento obtido ${ }^{10}$.

A partir dessas considerações seguem os resultados das pesquisas de campo realizadas na Central de Trabalho e Renda. Optamos por dois formatos:

1) Questionário com perguntas abertas e fechadas entregue aos usuários da Central de Trabalho e Renda, e outro questionário, com perguntas abertas, enviado por e-mail a dois empregadores acostumados a usar os serviço da CTR.

2) Grupo de foco: três grupos de discussão com oito integrantes em cada um, também todos usuários da CTR.

\section{QUESTIONÁRIO APLICADO}

Um questionário foi distribuído a 100 usuários da Central de Trabalho e Renda, de Santo André. Trata-se de uma pesquisa inicial para identificar o grau de informação que os trabalhadores possuem dos serviços oferecidos e, eventualmente, por quais veículos de comunicação (folhetos, jornal, boca a boca, funcionários etc.) esses trabalhadores foram informados.

Tal questionário também teve por objetivo coletar outras informações que possam subsidiar a preparação de uma outra pesquisa, mais aprofundada, a ser realizada segundo as técnicas do grupo de foco, ou grupo de discussão.
10. OROZCO GOMES, Guillermo. La investigación en comunicación desde la perspectiva cualitativa (A investigação em Comunicação a partir da perspectiva qualitativa). La Plata, Argentina: Un. Nacional de La Plata, 1997. p. 34. Tradução livre. 
A aplicação do questionário foi feita aleatoriamente pelo pesquisador durante a manhã de dois dias no salão da Central de Trabalho e Renda, onde os trabalhadores aguardam atendimento.

O único critério seletivo foi a exigência de que o trabalhador já fosse cadastrado na CTR e, portanto, já tivesse freqüentado pelo menos uma vez aquelas dependências. Isso aumentou as chances de os questionários serem respondidos por pessoas que já haviam tido algum contato com os serviços oferecidos pela CTR.

O questionário composto de oito perguntas (fechadas e abertas) foi entregue aos pesquisados para preenchimento. Os resultados foram os seguintes:

1) Como você soube da existência da Central de Trabalho e Renda?

Pelos amigos

$44 \%$

Pelos jornais

$30 \%$

Pelos familiares

$19 \%$

Pela televisão

$6 \%$

Pela internet

$3 \%$

Outros

$2 \%$

Pelo rádio

$1 \%$ ।

Por folhetos de divulgação $1 \%$ ।

2) Você poderia citar os serviços que a Central de Trabalho e Renda oferece? (Questão aberta)*

Mostra estar informado

Mostra estar pouco informado

$42 \%$

$2 \%$

Mostra não ter nenhuma informação $6 \%$

* Esses resultados foram elaborados a partir das citações dos usuários. Quando eram feitas até duas citações de serviços, utilizou-se o critério de classificar aquele usuário como de "pouco conhecimento". Quando houve mais de dois serviços citados, fica relativamente claro que o consulente "mostra conhecimento" do assunto. Nos casos em que há explicitamente escrito "não sei" ou outra resposta parecida, considerou-se que o usuário não tem nenhum conhecimento.

3) Dos serviços oferecidos, qual ou quais você considera mais importante? Pesquisa de vagas para emprego $79 \%$

Curso de orientação profissional $28 \%$

Palestras

$20 \%$

Emissão de Carteira de Trabalho

$15 \%$

Informações sobre FGTS

$14 \%$

Seguro-desemprego

$10 \%$

Outros

$1 \%$ I

4) Você já participou de alguma palestra?**

Não $73 \%$

Sim $\quad 27 \%$

** As palestras são ministradas pelos próprios consultores da CTR e tratam de temas sobre desemprego, como elaborar um currículo, como se portar em entrevistas, alternativas de trabalho como cooperativismo e empresas de autogestão etc. 
5) Se você já participou, como ficou sabendo?

Pelos alto-falantes no salão de espera ....................................................9\%

Convite pessoal de algum funcionário da CTR........................................7\%

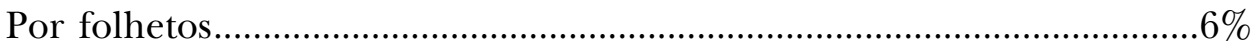

Por intermédio de um amigo ou conhecido.........................................2\%

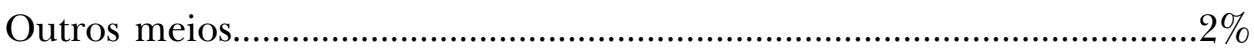

6) Para você, o que foi discutido na (nas) palestra(s):

Foi importante para minha vida profissional e pessoal ........................12\%

Foi muito importante para minha vida profissional e pessoal..............11\%

Foi pouco importante para minha vida profissional e pessoal ...............2\%

Não teve nenhuma importância para mim..............................................1\%

7) Por que você acha que existe tanto desemprego? (Questão aberta)***

Por causa do governo/políticos (altos impostos, alta taxa de juros, abertura econômica, falta de investimentos na economia, sistema capitalista, corrupção, informalidade no mercado de trabalho, crise econômica, desigualdade social) .

Por causa das empresas (muitas exigências, falta de registro em carteira, desejo insaciável de lucro, pouca disposição em abrir novos postos de trabalho, preferem empregar jovens, corte de mão-de-obra para baixar custos)

Baixa qualificação profissional dos trabalhadores (poucos investimentos na formação profissional das pessoas) .......................16\%

Falta de oportunidades oferecidas pelas empresas $14 \%$

Crescimento populacional que aumenta a concorrência por empregos $.4 \%$

Pouca solidariedade entre as pessoas (cada um pensa só em si, muitos têm dois empregos enquanto a maioria não tem nenhum) .............3\%

Excesso de aposentados ocupando vagas de pessoas que precisam trabalhar ..................................................................1\%

Globalização .......................................................................................1\%

${ }^{* * *}$ Nota-se que a soma dos percentuais desta questão excedem os $100 \%$. Isso ocorre porque em mais de $90 \%$ das respostas os pesquisados apontaram mais de um motivo que explicaria as razões do desemprego.

8) Se achar necessário, dê sugestões para melhorar a troca de informações entre a Central e os usuários. (Questão aberta)

Mais atenção e agilidade no atendimento ...............................................5\%

Possibilidade de pesquisar vagas por telefone/internet .........................4\%

Expor de maneira organizada as vagas oferecidas para consulta ...........2\%

Deixar funcionários da CTR à disposição para tirar dúvidas dos usuários durante o período de espera ................................................1\%

Enviar informes da CTR pelo correio ....................................................1\% 


\section{GRUPO DE DISCUSSÃO}

Com o intuito de ter uma avaliação mais detalhada dos serviços prestados pela Central de Trabalho e Renda, decidimos por uma pesquisa usando como metodologia a técnica de grupo de foco. Trata-se de uma modalidade de entrevista realizada em grupo composto por, no mínimo, seis e, no máximo, 12 pessoas que tenham interesses comuns. Esse grupo é conduzido por um moderador que segue um "roteiro com o propósito de atingir os objetivos pretendidos pelo pesquisador" 11 . Além dos pesquisados e do moderador, o grupo de foco é composto por um ou mais observadores. A intenção é criar um ambiente informal para que as pessoas se sintam à vontade para expressar suas idéias, expectativas, desejos e sentimentos.

Nas discussões em grupo, o mediador seguiu um roteiro contendo questões relacionadas a hábitos na procura por emprego, serviços da CTR, atendimento, ambiente de espera, dependências, conteúdo das orientações profissionais etc.

De acordo com as informações obtidas por meio das discussões dos grupos de foco, podemos identificar os seguintes pontos:

- A procura pelo emprego não mede esforços. Os candidatos se submetem a longas esperas e a percorrer grandes distâncias quando concorrem a uma vaga. Lêem jornais (de preferência gratuitos) e geralmente realizam outra atividade como hobby, além de bicos para ajudar (ou sustentar) o orçamento doméstico.

- Existe uma predisposição bastante grande para participar ou contribuir com qualquer tipo de atividade que a CTR venha a oferecer, sobretudo as relacionadas ao mundo do trabalho.

- A possibilidade de freqüentar cursos para o enriquecimento e atualização profissional é considerada de extrema importância para enfrentar o exigente mercado de trabalho.

- A Central de Trabalho e Renda, assim como outras agências de emprego, é reconhecida como entidade que facilita a vida do desempregado, que não precisa perambular aleatoriamente pelas empresas à procura de vagas.

- Os pesquisados afirmam que o bom atendimento depende muito da disposição e da personalidade do atendente. Querem que estes sejam atenciosos, saibam ouvir, mostrem dedicação na busca de uma vaga compatível com o perfil do trabalhador e, por fim, incentivem-no a não desistir do seu objetivo.

11. LEITÃO, Bárbara Júlia M. Grupos de foco: o uso da metodologia de avaliação qualitativa como suporte complementar à avaliação quantitativa realizada pelo Sistema de Bibliotecas da USP. São Paulo, 2003. $131 \mathrm{f}$. Dissertação de mestrado em Ciências da Comunicação, Escola de Comunicações e Artes da Universidade de São Paulo. p. 53.
- Gostariam que os empregadores fossem mais flexíveis no processo de seleção para uma vaga de emprego. Os trabalhadores querem ter a oportunidade de mostrar todas as suas qualidades profissionais e, com isso, aumentar suas chances de ocupar uma função que já tenham exercido, mas não possuem seu registro na carteira profissional, ou não consta nas cartas de apresentação. Na verdade, o contexto da palavra oportunidade, que aparece com freqüência em uma pergunta aberta do questionário, fica mais claro na pesquisa com os grupos de foco. Reclamam justamente de falta de oportunidade por parte do empregador, uma vez que este não leva em consideração informações importantes sobre o perfil 
profissional dos trabalhadores. Informações que muitas vezes não estão suficientemente destacadas em nenhum documento (carteira profissional, currículo, carta de apresentação etc.).

- Mostram-se dispostos a realizar alguma atividade durante o tempo em que esperam para ser atendidos, ainda que seja apenas assistir à TV. Há um interesse grande por informações, principalmente do mercado de trabalho, que poderiam ser veiculadas por intermédio de um telão ou por exemplares de jornais e revistas colocados à disposição dos trabalhadores.

- A pesquisa por vagas é um dos pontos principais de atenção. Gostariam que fosse mais ágil e rápida. É importante notar que o longo período de espera na CTR se deve, em grande parte dos casos, ao enorme número de trabalhadores que retornam à entidade apenas para saber se apareceu alguma vaga compatível com o seu perfil profissional. Muitos prefeririam uma consulta por serviço telefônico gratuito para, desse modo, não ter de se deslocar à CTR. Sugerem total remodelação do quadro no salão de espera onde ficam afixadas as vagas disponíveis do período.

- Problemas relacionados ao transporte coletivo são outro ponto de muita atenção por parte dos trabalhadores. A maioria dos empregadores, por contenção de gastos, nega-se a fornecer vale-transporte para quem é obrigado a tomar mais de dois ônibus. A concessão de vale-transporte pelas empresas é um direito regulamentado por lei e isso, na opinião dos pesquisados, acaba dificultando a conquista de uma vaga. O temor de um eventual processo judicial, no caso de um empregado não beneficiado reclamar do seu direito na Justiça, estaria inibindo as empresas a contratarem. Por isso, preferem que a CTR os encaminhem para empresas próximas a sua residência.

- As palestras são os principais itens apontados como diferencial em relação a outras agências de emprego. Elogiam a atividade e todos de alguma forma manifestaram interesse em participar. A opinião corrente entre os depoentes é que também as palestras servem de atualização para quem está fora do mercado de trabalho. Mesmo a que trata especificamente do tema desemprego é considerada importante e não cogitaram substituí-la ou, ainda, eliminá-la. Vale ressaltar que essa palestra é a menos procurada pelos trabalhadores que vão à Central de Trabalho e Renda.

- A divulgação das palestras é bastante falha, fato que também aparece explicitamente na pesquisa dos grupos de foco.

\section{PROPOSTA DE INTERVENÇÃO}

Diante dos resultados mostrados a partir das pesquisas de campo realizadas, sugerimos a elaboração de um plano de comunicação que intervenha nos segmentos e nos processos de atendimento ao trabalhador, nas relações com as empresas empregadoras e nas operações conjuntas desenvolvidas com a Prefeitura de Santo André. 
Esse plano de comunicação precisa levar em conta duas premissas fundamentais:

1) Aprimorar o diálogo com os usuários da Central de Trabalho e Renda, melhorando ou criando canais de interlocução.

2) Preparar o trabalhador para que tenha condições de escolher ou criar novas oportunidades de obtenção de renda, diante de uma escassez irreversível, ao que tudo indica, de vagas de emprego nos moldes tradicionais da economia.

Não é por acaso que na sociedade de produção e consumo de massa o que mais se dissemina como apelo de marketing é a idéia segundo a qual o cliente precisa ser tratado como se fosse único, especial, ou, para usar o jargão da moda, ter tratamento customizado. É inegável que ninguém quer ser atendido como apenas mais um nas organizações prestadoras de serviço, sejam públicas ou privadas. Cada vez mais as pessoas se manifestam com o nítido propósito de buscar canais de comunicação que lhes abram espaços para expressar suas opiniões, sentimentos, dúvidas, angústias, sugestões.

As pesquisas realizadas na Central de Trabalho e Renda remetem para essa mesma tendência: o trabalhador que procura a CTR quer ser ouvido e deseja que sua expressão seja respeitada de modo a estabelecer um diálogo, um relacionamento mais consistente que uma simples relação cliente/prestador de serviço.

Uma outra questão crucial é para onde encaminhar um contingente crescente de pessoas à procura de empregos que deixaram de existir ou que vêm minguando à medida que surgem novas técnicas de administração e de produção? Cabe ressaltar que o fenômeno não atinge apenas o setor secundário da economia. Comércio e serviços também cortam custos e adquirem novos métodos de administração utilizando equipamentos modernos que reduzem o uso de mão-de-obra.

Apresentar ao trabalhador outros caminhos de sobrevivência é mostrar que ele também pode ser útil não apenas no sistema produtivo onde prevalece a intensa concorrência entre trabalhadores pelo emprego tradicional, mas em diferentes possibilidades de obtenção de renda, tanto por meio de cooperativas, de empreendimentos populares baseados no microcrédito, quanto de empresas adquiridas pelos próprios funcionários pelo sistema de autogestão.

Essas alternativas em maior ou em menor grau já vêm sendo desenvolvidas pela CTR; no entanto, o momento socioeconômico exige que suas fronteiras sejam ampliadas no sentido de abarcar um número bem maior de trabalhadores que possuem chances mínimas de reingresso no mercado de trabalho formal, notadamente aqueles com baixíssima instrução ou há muito tempo sem ocupar função com carteira assinada.

Em suma, a Central de Trabalho e Renda, em conjunto com seus parceiros, deve, acima de tudo, priorizar a valorização da condição do trabalhador, não a do emprego.

\section{APRIMORAR OS PROCESSOS COMUNICACIONAIS}

Em primeiro lugar é necessário estreitar ainda mais a parceria desenvolvida entre a CTR e a Prefeitura de Santo André. Todas as ações que envolvam a formação e a geração de renda para o trabalhador precisam ser compartilhadas 
entre esses dois atores. A formulação e a programação de ações como cursos para o empreendedor popular, eventos ligados ao Banco do Povo e ao programa de Incubação de Cooperativas, além de atividades sobre requalificação profissional, precisam ser realizadas conjuntamente.

São de conhecimento geral as dificuldades financeiras por que passam entidades como a CTR, fundamentalmente dependentes de verbas públicas para funcionarem. Propor sugestões que acarretem investimentos além da capacidade financeira da entidade significa, na prática, manter tudo do jeito como está. No entanto, buscar parceiros privados para determinadas realizações bem definidas pode resultar em grandes ganhos operacionais, sem que haja nenhum tipo de desvirtuamento de convicções ou de diretrizes ideológicas.

Seria perfeitamente possível supor que existe interesse por parte das empresas, sobretudo as empregadoras que mantêm vínculos profissionais com a CTR, em patrocinar iniciativas ou compra de equipamentos (seja por meio de cotas, seja de financiamento exclusivo) que melhorem o atendimento e a formação do trabalhador.

De um lado, porque os candidatos remetidos pela agência para disputar as vagas nessas e em outras empresas puderam ter a oportunidade de ser mais bem avaliados e aprimorados na sua formação profissional.

De outro, porque a imagem da empresa patrocinadora será vista e reconhecida por milhares de pessoas, por meio de logomarcas ou mensagens institucionais eventualmente veiculadas em locais estratégicos nas dependências da CTR.

Dessa forma, poderiam tornar-se viáveis as sugestões a seguir:

- Criar um telecentro com tratamento acústico no ambiente e equipamentos de imagem e som, como videocassetes, DVDs e monitores de vídeo. Local próprio para exibição de filmes, documentários e programas de formação profissional ou de empreendedorismo, cursos de idiomas etc.

- Montar um laboratório de informática com computadores conectados à internet em banda larga, mais a instalação de impressoras. Tais equipamentos facilitariam a pesquisa por vagas e a de outros assuntos ligados ao mundo do trabalho, além da confecção de currículos e cartas de apresentação.

- Instalar um ou mais telões no salão de espera, conectados a um computador capaz de exibir instantaneamente informações das atividades da CTR, vagas de trabalho, notícias nacionais e internacionais, ou mesmo pequenos filmes e mensagens institucionais do poder público local e, eventualmente, dos patrocinadores.

- Reformar o quadro-mural onde são expostas as vagas de trabalho para consulta; seria recomendável ampliar seu tamanho e tornar mais legível suas informações.

- Melhorar o equipamento de som e as condições acústicas do salão de espera, de modo a tornar audíveis as mensagens transmitidas pelo sistema de alto-falantes. Seria recomendável ainda gravar, com recursos sonoros de estúdio, as mensagens de conteúdo recorrente, para chamar ainda mais a atenção dos usuários.

- Elaborar pesquisas periódicas para medir o grau de satisfação no atendimento dos usuários. E, a partir desses resultados, se possível com ajuda 
de consultores da área, realizar reuniões sistemáticas com os atendentes para que sejam devidamente informados.

- Melhorar e dar maior visibilidade ao quadro onde estão afixadas as informações sobre as palestras programadas do mês; outra opção seria divulgar as palestras pelo telão a ser instalado no salão de espera.

- Instalar no auditório, onde são realizadas as palestras, equipamento audiovisual com capacidade para projetar vídeos, gráficos e imagens que possam ilustrar os conteúdos dos temas apresentados e discutidos.

- Criar um sistema eletrônico de compartilhamento dos dados próprios, gerados tanto pela Prefeitura de Santo André quanto pela CTR.

- Intensificar as visitas periódicas às empresas da região, sobretudo às que não conhecem a fundo o trabalho da CTR, e convidar os potenciais empregadores para que visitem as instalações da Central. Simultaneamente com essa atividade, realizar pesquisas de opinião com os recrutadores das empresas que utilizam o serviço da CTR. As visitas de representantes da CTR às empresas, oportunidade criada para que se estreitem contatos, foi elogiada pela diretora do departamento de Recursos Humanos, Formação e Desenvolvimento da Pirelli Pneus S.A., Ana Edna Lessio Vaz da Silva, empresa que freqüentemente se utiliza dos serviços da CTR.

- Melhorar o mecanismo de pesquisas de vagas no site da CTR na internet e/ou criar um sistema de consulta pelo telefone. Formar parcerias com provedores da região para que estes veiculem as vagas de empregos oferecidas pela CTR.

- Criar um banco de dados onde serão cadastrados todos os trabalhadores contratados por intermediação da CTR, bem como acompanhar pelo período de um ano os destinos profissionais desses trabalhadores.

Resumo: O desemprego pode ser considerado hoje a principal preocupação das famílias dos trabalhadores brasileiros. Um problema que a história do capitalismo sempre tratou como circunstancial, mas, devido a sua persistência nos últimos anos, muitos estudiosos já o consideram estrutural. Este trabalho aborda tal assunto por intermédio da Central de Trabalho e Renda, uma agência pública de emprego e renda. O objetivo principal é elaborar uma proposta de comunicação para essa entidade, que lida diariamente com o fato de que não há emprego suficiente para todos.

Palavras-chave: emprego, desemprego, renda, formação profissional, comunicação pública, Central de Trabalho e Renda.
Abstract: The unemployment may be considerate the main concern of Brazilian workers nowadays. A problem that the history of capitalism has always treated as circumstantial, but due to its persistence in the last year, many scholars consider it structural. This study approaches this subject through Central de Trabalho e Renda, a public agency of jobs and revenue. The main objective is to elaborate a proposal of communication to this entity, that daily deals with the fact that do not exist job enough to everyone.

Keywords: employment, unemployment, revenue, professional background, public communication, Central de Trabalho e Renda. 